\section{RTh 03}

IN VITRO ASSAY OF RADIORESPONSE OF HUMAN TUMORS W. Hinkelbein, M. Berg., A. Würdinger, H.H. Fiebig (granted by DFG, Hi 368/1-1) The "radiosensitivity" of human tumors estabTished in serial passage in nude mice was tested by a modified MAMBURGER and SALMON colony assay. A11 tumors ( 3 p 7 ates each) were irradiated with $1,1.5,2.5,4.5,8,10,15$ Gy $x$-ray $(250 \mathrm{KV}, 3.5 \mathrm{~mm} A 1-f i$ ter $)$ followed by incubation at $37^{\circ} \mathrm{C}, 7 \% \mathrm{CO}_{2}$ and humidity of $100 \%$. The colonies were vital stained 1 day before counting by a modified image processor OMNICON FAS III (colony size 60-80 $\mu$ ). T/Cvalues were calculated as a percental quotient of mean values from treatment and control groups. Only tests with a log-linear survivaldose dependency were considered. "Radiosensitivity" was defined as $\mathrm{T} / \mathrm{C}$ value $<30$ at $1.5-4$ Gy or $<10$ at 5 Gy and graduated as shown in table 1:

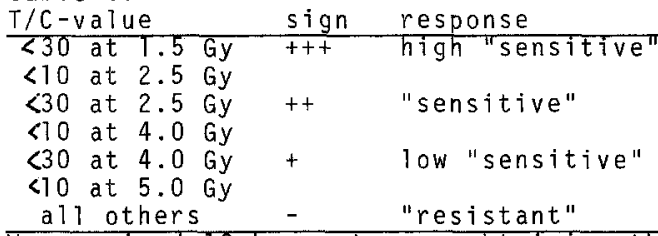

We examined 18 human tumors obtaining the

following results:

high "sensitive": 1 seminoma, 1 small-cell lung cancer / "sensitive": 1 renal cancer, 2 soft tissue sarcamas, 3 squamous-cell lung cancers $/$ low "sensitive": 2 ma1. melanomas, 1 squamouscell lung cancer, 11 arge-cell lung cancer / "resistant": 2 mal. melanomas, 2 adenocarcinomas of the lung, 1 gastric cancer.

Dr.W. Hinkelbein, Abt. Strahlentherapie, Hugstetter Str. 55, 7800 Freiburg

\section{RTh 04}

Combination of interstitial Hyperthermie with high dose rate afterloading radiation therapy.

P. Kneschaurek, G. Ries, M. Weisser, A. Breit

The use of hyperthermia, especially in combination with radiation gets increasingly important in clinical cancer therapy. The main problem of local hyperthermia is still the safe and reliable heating of the tissue, the mapping of the actual temperature distribution, and the fitting of a given isotherme to the target volume.

We developed a system for the combination of interstitial hyperthermia with interstitial high dose rate afterloading therapy. The needles which are used for guiding the radioactive source can also be used as electrodes for RFheating. The outermost part of the needles that are not placed within the target volume are isolated. Consequently the r.f. current and therefore the powerdeposition is $1 i-$ mited to the target volume. Our microcomputer controlled system allows to connect simultaneously or sequentially different needles to the r.f. power amplifier and is thus able to realize a great number of different heating patterns. The actual temperatures are recorded by thermistors located inside the needle electrodes. Each needle contains up to 3 thermometers so that also the temperature distribution in the direction of the needles is recorded. The microcomputer adjusts the r.f. power level to maintain a given temperature. Temperature distributions have been measured in phantoms.

The needle geometry has carefully to be planned so that both the temperature- and the dose distribution matches the target volume. Examples are given.

The reported results of this combination treatment are impressive. Contrarily to these groupes we are using high dose rate afterloading therapy instead of low dose rate sources. Because of the short irradiation time we are able by a carefully choosen time intervall between radiation and hyperthermia to achieve a high therapeutic gain factor. Simultaneously the discomfort of the patient is reduced.

Institut für Strahlentherapie der Techn. Univ. München Ismaninger Str. 15, 8000 München 80

\section{RTh 05}

EXPERIENCES WITH AFTERLOADING - AS INTRACAVITAL RADIOTHERAPY - OF NON-GYNECOLOGIC TUMORS. U. Freund, M. Wannenmacher, G. Bruggmoser Afterloading technique - developed in its fundamentals in the early sixties by Henschke was initially intended to replace radium therapy of gynecologic tumors. The main goal of this modern brachytherapy is to avoid any radiation exposure of the medical personnel. Intracavitary ind intersitial radiotherapy has the following advantages: 1.) high radiation dose applied to the target volume. 2.) steep doseslape beyond the target volume. 3.) low exposure of the surrounding healthy tissue.

4.) reduction of percutaneous irradiation together with shorter hospitalization period. During the last three years we have used this method in the Department of Radiotherapy in Freiburg as additional therapy for oesophagus and rectum carcinomas together with percutaneous irradiation. The following further indications are possible and are applied in our department: intracavital: - intrabronchial (in combination with laser therapy) - nasopinaryn-

geal interstitial: - subcutaneous tumors mamma carcinoma - tangue tumors - anal carcinoma. For this therapy we use the Gamma-Med-iapparatus (Isotopen-Technik, Dr. Sauerwein, GmbH). Dosage and fractioning are still subject to experiences. We presently use the following concept: - Individual dose of 5 Gy in a source distance of $2.5 \mathrm{~mm}$ using a flexible tube (e.g. oesophagus) - Individual dose of 5 Gy in a source distance of $5.0 \mathrm{~mm}$ with a rigid distance-holder (e.g. rectum). Fractionation $3 \times 5$ Gy in weekly intervals.

Abteilung Strahlentherapie des Univ.-Klinikums Hugstetter Straße 55, D-7800 Freiburg/Breisgau

\section{RTh 06}

PALLIATION OF PAIN FROM BONE METASTASES USING MULTIPLE DAILY FRACTIONS OF RADIATION. G.J.Steiger, J.H.Karstens and J.Ammon.

Metastatic bone disease is the most common cause of severe pain in patients with cancer. The efficiency of radiation therapy in providing relief from pain caused by bone metastases has been well established. Common practice has been to deliver a fractionated radiation therapy course spread over several weeks. It seems obvious that faster pain relief would be advantageous in many ways. In this study 23 patients, with a variety of primary tumors, have been treated for palliation of pain with radiotherapy using an accelerated regimen of multiple daily fractions. Patients received in general three treatments daily with 3 - 4 hour intervals on three consecutive days. The single dose applied was between 1.5 and 2.5 Gy depending on field size and site.The radiation portals included all sites of bone metastases except those in cervical, thoracical and upper lumbar spine. Good or complete pain relief, generally within one or two days after completion of treatment, was observed in all 18 patients with breast cancer, which could be documented by the reduction of pain medication. Less impressive response was obtained in carcinomas of bronchus or prostate (5/23), but the actual numbers for these tumors are too small to draw any conclusions. Enhanced side effects like acute skin reactions were not observed. The degree of remineralisation was similar as with conventional fractionation. This study shows that multiple daily fractions of radiation are at least for rapid palliation of pain from bone metastases in breast cancer an effective method.

Abt. Strahlentherapie, Med. Fakultät, Klinikum RWTH Aachen, D - 5100 Aachen, Pauwelsstr. 